The Astrophysical Journal, 485:689-696, 1997 August 20

(C) 1997. The American Astronomical Society. All rights reserved. Printed in U.S.A.

\title{
NEW DISSOCIATIVE RECOMBINATION PRODUCT BRANCHING FRACTIONS AND THEIR EFFECT ON CALCULATED INTERSTELLAR MOLECULAR ABUNDANCES
}

\author{
ERIC Herbst \\ Departments of Physics and Astronomy, Ohio State University, Columbus, OH 43210; herbst@ohstpy.mps.ohio-state.edu \\ AND \\ H.-H. LEE \\ Department of Physics, Ohio State University, Columbus, OH 43210 \\ Received 1997 January 28; accepted 1997 March 24
}

\begin{abstract}
Recent storage ring measurements of the complete product distributions for the dissociative recombination of assorted polyatomic ions $\left(\mathrm{H}_{3}^{+}, \mathrm{H}_{2} \mathrm{O}^{+}, \mathrm{H}_{3} \mathrm{O}^{+}, \mathrm{CH}_{3}^{+}\right)$show that there is significantly more fragmentation than previously believed. Generalizing these results, we consider the effect on gas-phase chemical models of dense interstellar clouds when a greater degree of fragmentation is assumed for the products of dissociative recombination reactions. In general, we find salient model results to be surprisingly insensitive to the change. We also generalize some conflicting experimental results for the branching fractions of $\mathrm{H}_{3} \mathrm{O}^{+}+e$ obtained in a flowing afterglow experiment. With this set of generalized branching fractions in our chemical model, there is a stronger change from previous results, especially for more saturated molecules, which are now difficult to produce in the gas phase.
\end{abstract}

Subject headings: ISM: clouds - ISM: molecules - molecular processes

\section{INTRODUCTION}

Although the rate coefficients for dissociative recombination reactions between polyatomic molecular ions and electrons are reasonably well known (Mitchell 1990; Adams \& Smith 1988), save possibly for certain exceptions such as $\mathrm{H}_{3}^{+}+e^{-}$(Sundström et al. 1994; Dalgarno 1994; Smith \& Spanel 1993), the branching fractions for the various sets of neutral fragments are less well determined by laboratory measurements (Adams 1992). Theoretical determinations of the product branching fractions have produced differing results (Galloway \& Herbst 1991; Bates 1989) and must be regarded as at best partially reliable. Since dissociative recombination reactions represent the final step in ionmolecule syntheses of interstellar molecules, this lack of knowledge has always added a vexing uncertainty to the results of chemical models of interstellar clouds. Almost a decade ago, Millar et al. (1988) considered the sensitivity of model results to differing theoretical predictions of dissociative recombination branching fractions.

In recent years, laboratory experiments on thermalized molecular ions in a flowing afterglow (Adams 1992) have been undertaken to determine the branching fractions to within $5 \%-10 \%$ for channels involving the radical $\mathrm{OH}$ (Herd, Adams, \& Smith 1990) and the $\mathrm{H}$ atom (Adams et al. 1991). Although exciting, these sets of experiments do not typically yield the branching fractions for all relevant channels. In a breakthrough, Williams et al. (1996) managed to determine the complete product distribution for the dissociative recombination reaction between $\mathrm{H}_{3} \mathrm{O}^{+}$and electrons by converting $\mathrm{O}$ atom product into $\mathrm{OH}$ using the reaction with germane $\left(\mathrm{GeH}_{4}\right)$, thus enabling a measurement of $\mathrm{O}, \mathrm{OH}$, and $\mathrm{H}$ products. This dissociative recombination reaction has four sets of possible exothermic products:

$$
\begin{aligned}
\mathrm{H}_{3} \mathrm{O}^{+}+e & \rightarrow \mathrm{OH}+2 \mathrm{H} \\
& \rightarrow \mathrm{OH}+\mathrm{H}_{2} \\
& \rightarrow \mathrm{O}+\mathrm{H}+\mathrm{H}_{2} \\
& \rightarrow \mathrm{H}_{2} \mathrm{O}+\mathrm{H}
\end{aligned}
$$

with product fractions determined to be $0.29,0.36,0.30$, and 0.05 , respectively. The uncertainties in these values were not reported; since the $\mathrm{H}_{2} \mathrm{O}+\mathrm{H}$ channel is determined by subtraction of channels with $5 \%$ uncertainties, it may well not occur at all. Although the phase space calculations of Galloway \& Herbst (1991) had correctly predicted more $\mathrm{OH}$ than $\mathrm{H}_{2} \mathrm{O}$, the very small amount of water and the prominence of the two three-body channels were not expected.

Somewhat after the flowing afterglow work on the products of dissociative recombination reactions was begun, experiments on such reactions using storage rings were undertaken to study both total rates and product branching fractions. In storage rings, molecular ions have much time to cool internally before reacting with electrons; lack of such cooling had bedeviled a variety of earlier experiments. The first branching results concerned the ions $\mathrm{H}_{3}^{+}$and $\mathrm{H}_{2} \mathrm{D}^{+}$, where it was found that the channel in which three atoms are formed occurs with branching fractions of 0.75 and 0.73, respectively (Datz et al. 1995a, 1995b; Larsson et al. 1996). Most recently, complete product distributions for the dissociative recombination of the cold polyatomic ions $\mathrm{H}_{2} \mathrm{O}^{+}, \mathrm{H}_{3} \mathrm{O}^{+}$, and $\mathrm{CH}_{3}^{+}$have been measured in a storage ring (Vejby-Christensen et al. 1997). These experiments also show surprisingly strong three-body product channels, although there is a strong disagreement with the results of Williams et al. (1996) for $\mathrm{H}_{3} \mathrm{O}^{+}+e$. Specifically, the storage ring results for the four product channels (1)-(4) are $0.48,0.18,0.01$, and 0.33 with estimated uncertainties of 0.05-0.10 (Vejby-Christensen et al. 1997). The major disagreement concerns the product fractions for the $\mathrm{O}+\mathrm{H}$ $+\mathrm{H}_{2}$ and $\mathrm{H}_{2} \mathrm{O}+\mathrm{H}$ channels that, together, account for about $\frac{1}{3}$ of the products in both experiments. VejbyChristensen et al. (1997) measured that this fraction is virtually all in the $\mathrm{H}_{2} \mathrm{O}+\mathrm{H}$ channel, whereas Williams et al. (1996) measured it to be virtually all in the $\mathrm{O}+\mathrm{H}+\mathrm{H}_{2}$ channel. The discrepancy is so far unexplained. Interestingly, the 0.33 fraction for $\mathrm{H}_{2} \mathrm{O}+\mathrm{H}$ measured in the storage ring is virtually identical to the value used in most current interstellar chemical models (Lee, Bettens, \& Herbst 
1996a; Millar, Farquhar, \& Willacy 1997). In addition, the measured size of this channel is similar to the 0.40 branching fraction measured with the storage ring for the $\mathrm{CH}_{2}$ $+\mathrm{H}$ channel of $\mathrm{CH}_{3}^{+}+e$ (Vejby-Christensen et al. 1997).

Summarizing the results of recent work by both the flowing afterglow and storage ring techniques, we can say securely that three-body product channels are prominent for the smaller molecular ions studied so far, with total branching fractions of $0.75\left(\mathrm{H}_{3}^{+}\right), 0.73\left(\mathrm{H}_{2} \mathrm{D}^{+}\right), 0.68\left(\mathrm{H}_{2} \mathrm{O}^{+}\right)$, $0.49-0.59\left(\mathrm{H}_{3} \mathrm{O}^{+}\right)$, and $0.46\left(\mathrm{CH}_{3}^{+}\right)$, but that there remains some doubt about the size of individual channels in the one system for which two different techniques have been used to characterize the product distribution totally.

The importance of three-body channels can be understood in a variety of ways. One possibility, considered by Bettens \& Herbst (1995), is that the primary products of reaction are two-body channels, but the generally large energy of reaction goes partially into vibrational energy of the products and not totally into relative translational energy. If a two-body product channel consists of an atom and a molecule, sufficiently large amounts of vibrational energy in the one molecular species can lead to secondary fragmentation via unimolecular decay (Bettens \& Herbst 1995). For the $\mathrm{H}_{2} \mathrm{O}+\mathrm{H}$ and $\mathrm{CH}_{2}+\mathrm{H}$ channels, there can be sufficient vibrational energy produced in water and methylene $\left(\mathrm{CH}_{2}\right)$, respectively, to cause their decomposition into the detected three-body channels. If this mechanism is what is actually transpiring, three-body product channels will be generally prominent.

There is a second explanation for three-body channels, however. Two-body primary product channels with atoms and/or molecules in excited electronic states may be appreciable, a possibility that had been considered more than two decades ago by Herbst \& Klemperer (1973). If a primary molecular product is formed in a repulsive electronic state, it will decompose into secondary products, forming threebody channels. If this is indeed what is happening, the result cannot easily be generalized to other polyatomic ionelectron reactions, since stable electronic states also exist for neutral molecular products, and in these states, the energy of reaction can be safely radiated away, leading to stable two-body channels with species in their ground electronic states.

Given the present lack of understanding, it is difficult to make firm generalizations based on the experimental results reported so far. Still, it is important in our view to determine the possible effect on chemical models of interstellar clouds if, based on recent experiments, a greater degree of fragmentation is generally assumed for the products of dissociative recombination than has been assumed in the past, presumably in part because the first of the two mechanisms discussed above is operative. To accomplish this goal, we have reestimated all of the polyatomic ion-electron branching fractions in our current large model networks (Lee et al. 1996a) for ions with four or more atoms, assigning multibody product channels larger probabilities than heretofore if secondary fragmentation of binary channels is energetically and sterically possible. In this reestimation, we have used the most up-to-date thermodynamic data available, in many cases calculated by ourselves (Bettens \& Herbst 1995). We have then calculated molecular abundances for dense interstellar clouds with the new branching fractions and compared them with previously calculated abundances.

\section{RATES AND NEW BRANCHING FRACTIONS}

For the total rates of dissociative recombination reactions involving ions with four or more atoms, we have used measured rate coefficients $k$ when available (Adams \& Smith 1988). No overall rates are available for the majority of systems, and we have chosen the following rates based on the results for measured reactions: for ions with three or more hydrogen atoms, $k=1.0 \times 10^{-6}(T / 300)^{-0.3} \mathrm{~cm}^{3} \mathrm{~s}^{-1}$, otherwise $k=3.0 \times 10^{-7}(T / 300)^{-0.5} \mathrm{~cm}^{3} \mathrm{~s}^{-1}$. At a temperature of $10 \mathrm{~K}$, the former rate coefficient is $2.77 \times 10^{-6}$ $\mathrm{cm}^{3} \mathrm{~s}^{-1}$, while the latter is $1.64 \times 10^{-6} \mathrm{~cm}^{3} \mathrm{~s}^{-1}$. Although our previous calculations included both sets of rates for unstudied dissociative recombination reactions, the choice of which to use was not made consistently in all cases.

Two sets of new branching fractions have been chosen with the assumption that thermodynamically allowed and sterically reasonable assorted two-body, three-body, and multibody exit channels have equal branching fractions except for atom-molecule two-body channels in which the molecule can itself decompose to smaller fragments. These latter channels, in which the atom is invariably hydrogen, are assigned a branching fraction of 0.30 or 0.05 depending on the model calculation. The first value is in accord with the storage ring experiments of Vejby-Christensen et al. (1997) while the second value is in accord with the flowing afterglow results of Williams et al. (1996) on the $\mathrm{H}_{3} \mathrm{O}^{+}+e$ system. In these two model networks we have, in addition to the large number of new estimates, used the actual storage ring results of Vejby-Christensen et al. (1997) for the first model and the flowing afterglow results for the second model for the specific molecules for which data are available. A few H-molecule channels with secondary dissociation allowable thermodynamically but unlikely sterically or marginally allowable thermodynamically are given branching fractions of 0.10 in the second model. Not all possible exothermic channels are considered for each ion, especially the larger ions; rather, the list is representative and includes much more extensive breakup even for twobody channels than previous estimates, in which the skeletal structure of large ions was assumed to be rather stable (Herbst \& Leung 1989). The greater degree of fragmentation in both sets of estimated branching fractions might be expected to reduce the abundances of the more complex molecules in our reaction network. In addition, the low fraction assigned to $\mathrm{H}$ atom-molecule channels for the model based on the work of Williams et al. (1996) might be expected to reduce the abundance of saturated (H-rich) molecules such as water and methanol $\left(\mathrm{CH}_{3} \mathrm{OH}\right)$ especially. It must be remembered, however, that most larger ions in our network are highly unsaturated (H-poor) and involve skeletal structures with strong chemical bonds. Severe fragmentation of such ions in dissociative recombination reactions is often thermodynamically impossible. For some of the largest ions in the model (10-13 atoms), we have estimated branching fractions based on the statistical calculation of Bettens \& Herbst (1995) in place of the assumption of equal branching fractions because this calculation should be accurate in the limit of large molecular ions. In the statistical calculation, the more exothermic channels are calculated to have larger branching fractions. Radiative stabilization of the parent neutral species, an important channel for recombination reactions between very large 
positive ions and electrons (Bettens \& Herbst 1995), has not been considered here.

In Table 1, we present a subset of previously used and new branching fractions based on the storage ring (" 0.30 case") and flowing afterflow (" 0.05 case") results. (Complete sets of new branching fractions can be obtained from the authors.) A discussion of some representative systems in Table 1 might be useful. For $\mathrm{C}_{2} \mathrm{H}_{3}^{+}+e^{-}$the product channel $\mathrm{C}_{2} \mathrm{H}_{2}+\mathrm{H}$ can dissociate secondarily into $\mathrm{C}_{2} \mathrm{H}+2 \mathrm{H}$ and is given branching fractions of 0.30 and 0.05 in the two new cases considered, whereas for $\mathrm{C}_{4} \mathrm{H}_{2}^{+}+e^{-}$ the analogous $\mathrm{C}_{4} \mathrm{H}+\mathrm{H}$ channel is stable and is treated analogously to all other channels in the 0.05 case. The $\mathrm{HC}_{3} \mathrm{~N}+\mathrm{H}$ channel for the $\mathrm{C}_{3} \mathrm{H}_{2} \mathrm{~N}^{+}+e^{-}$reaction is marginally stable (unless virtually all of the product energy goes into vibration) and is accorded a branching fraction of 0.10 in the 0.05 case. The newly adopted branching fractions for the dissociative recombination of the saturated $\mathrm{CH}_{3} \mathrm{OH}_{2}^{+}$ ion illustrate the increased importance of three-body channels for H-rich ions with relatively weak chemical bonds. The $\mathrm{C}_{9}^{+}+e^{-}$reaction is assumed to produce product channels of equal probability for all possible fragmentations of the parent neutral; these (two-body) channels are not very different energetically. Note the increased fragmentation compared with the previous branching fractions, even though three-body channels are not possible. The $\mathrm{C}_{9} \mathrm{H}_{2}^{+}$ $+e^{-}$reaction is, based on statistical considerations, assumed to produce the very exothermic and quite accessible and stable $\mathrm{C}_{9} \mathrm{H}+\mathrm{H}$ product channel with a branching fraction of 0.50 , while four other channels divide the remainder of the product fraction (Bettens \& Herbst 1995).

\section{MODEL CALCULATIONS AND RESULTS}

We have run pseudo-time-dependent gas-phase models for dense interstellar clouds at a temperature of $10 \mathrm{~K}$ and a fixed gas density $n_{\mathrm{H}}$ of $2 \times 10^{4} \mathrm{~cm}^{-3}$. The so-called "new standard" model of Bettens, Lee, \& Herbst (1995) has been used. The model, which contains approximately 4000 gasphase reactions involving over 400 species, and which is based on the previous model of Herbst \& Leung (1989), has been augmented with a small number of exothermic deprotonation reactions between protonated ions and water:

$$
\mathrm{AH}^{+}+\mathrm{H}_{2} \mathrm{O} \rightarrow \mathrm{A}+\mathrm{H}_{3} \mathrm{O}^{+},
$$

where $\mathrm{A}$ is a neutral molecule. These reactions, previously omitted, might assume more importance if, assuming the flowing afterflow results to be representative, dissociative recombination channels leading to $\mathrm{A}$ from $\mathrm{AH}^{+}$are downgraded.

The new standard model is quite successful in reproducing observed abundances of molecules in TMC-1 (Herbst \& Leung 1989; Bettens et al. 1995) at so-called "early times" of $10^{4}-10^{5} \mathrm{yr}$. It does not contain a variety of large rates for neutral-neutral reactions, even though a limited number of experimental measurements have shown these reactions can occur rapidly at low temperatures (Sims \& Smith 1995). The similarly successful UMIST network (Millar et al. 1997) contains large rates for only those neutral-neutral reactions that have been measured to be rapid in the laboratory. Other model networks, such as the "new neutral-neutral" model and "model 4," have also been discussed by Bettens et al. (1995). Based on unproven

TABLE 1

Branching Fractions for Selected Dissociative Recombination Reactions

\begin{tabular}{|c|c|c|c|c|c|c|c|}
\hline \multirow{2}{*}{$\frac{\text { Reactant }}{\mathrm{C}_{2} \mathrm{H}_{3}^{+} \ldots \ldots \ldots \ldots}$} & \multirow[b]{2}{*}{$e^{-}$} & \multicolumn{3}{|c|}{ Products } & \multirow{2}{*}{$\begin{array}{c}0.30 \text { Case } \\
0.30\end{array}$} & \multirow{2}{*}{$\begin{array}{c}0.05 \text { Case } \\
0.05\end{array}$} & \multirow{2}{*}{$\frac{\text { Old Fraction }}{0.50}$} \\
\hline & & $\mathrm{C}_{2} \mathrm{H}_{2}$ & $\mathrm{H}$ & & & & \\
\hline & & $\mathrm{C}_{2} \mathrm{H}$ & $2 \mathrm{H}$ & & 0.23 & 0.32 & \\
\hline & & $\mathrm{C}_{2} \mathrm{H}$ & $\mathrm{H}_{2}$ & & 0.23 & 0.32 & 0.50 \\
\hline & & $\mathrm{CH}_{2}$ & $\mathrm{CH}$ & & 0.23 & 0.32 & \\
\hline \multirow{4}{*}{$\mathrm{C}_{4} \mathrm{H}_{2}^{+} \ldots \ldots \ldots$} & $e^{-}$ & $\mathrm{C}_{4} \mathrm{H}$ & $\mathrm{H}$ & & 0.30 & 0.25 & 0.50 \\
\hline & & $\mathrm{C}_{4}$ & $\mathrm{H}_{2}$ & & 0.23 & 0.25 & 0.50 \\
\hline & & $\mathrm{C}_{3} \mathrm{H}$ & $\mathrm{CH}$ & & 0.23 & 0.25 & $\ldots$ \\
\hline & & $\mathrm{C}_{2} \mathrm{H}$ & $\mathrm{C}_{2} \mathrm{H}$ & & 0.23 & 0.25 & \\
\hline \multirow[t]{5}{*}{$\mathrm{C}_{3} \mathrm{H}_{2} \mathrm{~N}^{+} \ldots \ldots$} & $e^{-}$ & $\mathrm{HC}_{3} \mathrm{~N}$ & $\mathrm{H}$ & & 0.30 & 0.10 & 0.25 \\
\hline & & $\mathrm{C}_{3} \mathrm{~N}$ & $2 \mathrm{H}$ & & 0.23 & 0.30 & \\
\hline & & $\mathrm{C}_{3} \mathrm{~N}$ & $\mathrm{H}_{2}$ & & 0.23 & 0.30 & 0.25 \\
\hline & & $\mathrm{C}_{2} \mathrm{H}$ & HNC & & 0.23 & 0.30 & \\
\hline & & $\mathrm{C}_{2} \mathrm{H}_{2}$ & $\mathrm{CN}$ & . & & & 0.50 \\
\hline \multirow[t]{5}{*}{$\mathrm{CH}_{3} \mathrm{OH}_{2}^{+} \ldots \ldots$} & $e^{-}$ & $\mathrm{CH}_{3} \mathrm{OH}$ & $\mathrm{H}$ & & 0.30 & 0.05 & 0.50 \\
\hline & & $\mathrm{CH}_{3}$ & $\mathrm{OH}$ & $\mathrm{H}$ & 0.18 & 0.24 & $\ldots$ \\
\hline & & $\mathrm{CH}_{3}$ & $\mathrm{H}_{2} \mathrm{O}$ & & 0.18 & 0.24 & \\
\hline & & $\mathrm{H}_{2} \mathrm{CO}$ & $\mathrm{H}_{2}$ & $\mathrm{H}$ & 0.18 & 0.24 & 0.50 \\
\hline & & $\mathrm{CH}_{2}$ & $\mathrm{H}_{2} \mathrm{O}$ & $\mathrm{H}$ & 0.18 & 0.24 & \\
\hline \multirow[t]{5}{*}{$\mathrm{C}_{5} \mathrm{H}_{3}^{+} \ldots \ldots \ldots \ldots$} & $e^{-}$ & $\mathrm{C}_{5} \mathrm{H}_{2}$ & $\mathrm{H}^{2}$ & & 0.30 & 0.20 & 0.50 \\
\hline & & $\mathrm{C}_{5} \mathrm{H}^{2}$ & $\mathrm{H}_{2}$ & & 0.18 & 0.20 & 0.50 \\
\hline & & $\mathrm{C}_{4} \mathrm{H}_{2}$ & $\mathrm{CH}$ & & 0.18 & 0.20 & $\ldots$ \\
\hline & & $\mathrm{C}_{3} \mathrm{H}_{2}$ & $\mathrm{C}_{2} \mathrm{H}$ & & 0.18 & 0.20 & $\ldots$ \\
\hline & & $\mathrm{C}_{3} \mathrm{H}^{2}$ & $\mathrm{C}_{2} \mathrm{H}_{2}$ & & 0.18 & 0.20 & \\
\hline \multirow[t]{4}{*}{$\mathrm{C}_{9}^{+}$} & $e^{-}$ & $\mathrm{C}_{8}$ & $\mathrm{C}$ & & 0.25 & 0.25 & 0.50 \\
\hline & & $\mathrm{C}_{7}$ & $\mathrm{C}_{2}$ & & 0.25 & 0.25 & 0.50 \\
\hline & & $\mathrm{C}_{6}$ & $\mathrm{C}_{3}$ & & 0.25 & 0.25 & $\ldots$ \\
\hline & & $\mathrm{C}_{5}$ & $\mathrm{C}_{4}^{3}$ & & 0.25 & 0.25 & $\cdots$ \\
\hline \multirow[t]{5}{*}{$\mathrm{C}_{9} \mathrm{H}_{2}^{+}$} & $e^{-}$ & $\mathrm{C}_{9} \mathrm{H}$ & $\mathrm{H}^{+}$ & & 0.50 & 0.50 & 0.50 \\
\hline & & $\mathrm{C}_{9}$ & $\mathrm{H}_{2}$ & & 0.13 & 0.13 & 0.50 \\
\hline & & $\mathrm{C}_{7} \mathrm{H}$ & $\mathrm{C}_{2} \mathrm{H}$ & & 0.13 & 0.13 & $\ldots$ \\
\hline & & $\mathrm{C}_{6} \mathrm{H}$ & $\mathrm{C}_{3} \mathrm{H}$ & & 0.13 & 0.13 & $\ldots$ \\
\hline & & $\mathrm{C}_{5} \mathrm{H}$ & $\mathrm{C}_{4} \mathrm{H}$ & & 0.13 & 0.13 & $\ldots$ \\
\hline
\end{tabular}


yet reasonable extrapolation, the new neutral-neutral model contains large rates for many neutral-neutral reactions, but cannot match the observed interstellar abundances of complex molecules at any time with the standard "low" elemental carbon-to-oxygen ratio of 0.4 . Model 4 contains a more limited number of rapid neutral-neutral reactions and is more successful with the standard carbon-to-oxygen ratio. Work on comparing the results of these models with observation for higher carbon-to-oxygen elemental ratios is still in progress (Terzieva \& Herbst 1997), but does show a general improvement for complex molecules. We use the new standard model here as a point of departure because it still represents our most successful chemical model of interstellar clouds. Detailed information including the initial fractional abundances used in the model as well as calculated fractional abundances as functions of time and gas density have been recently presented in the literature (Lee et al. 1996a). An extension of the model to inhomogeneous clouds with significant external photon penetration has also been accomplished (Lee et al. 1996b). We note that the solutions to all of our time-dependent models fall into the class of "low ionization phase" solutions. Solutions representing another chemical phase known as the "high ionization phase" have also been obtained (Le Bourlot, Pineau des Forêts, \& Roueff 1995). Here we focus on changes produced by the revisions in the estimated branching fractions for dissociative recombination reactions. We have also investigated some analogous changes to the new neutralneutral model results, but do not present these results here in any detail.

Table 2 contains a comparison in the form of ratios between new and old molecular abundances with the updated new standard model network. Ratios are presented for both the 0.30 and 0.05 cases at two times: steady state, which is reached after $10^{7}-10^{8} \mathrm{yr}$, and early time $\left(3 \times 10^{4}\right.$ yr), a time at which abundances of complex molecules are at or near their peak. Only species that reach a fractional abundance of at least $10^{-12}$ at some time period are included in the tables. Since many species show small changes in abundance, only those atoms and molecules for which abundances change by at least an order of magnitude in one or both cases at one time or another are presented. It can be seen that the number of molecules in this table is relatively small $(\approx 10 \%$ of the number of species). If one removed the constraint on a minimum abundance, 76 species $(\approx 20 \%$ of the total) would be included in Table 2 , proving that the abundances of most molecules are not affected greatly by the new branching fractions. There is a

TABLE 2

Selected Ratios of Molecular Abundances with New Branching Fractions to Those With Old Branching FraCtions

\begin{tabular}{|c|c|c|c|c|}
\hline Species & 0.30 Case ET & 0.30 Case SS & 0.05 Case ET & 0.05 Case SS \\
\hline $\mathrm{SiC}$. & $1.1(+00)$ & $1.3(+00)$ & $2.1(+00)$ & $1.5(+01)$ \\
\hline $\mathrm{H}_{2} \mathrm{O} \ldots \ldots \ldots \ldots$ & $1.1(+00)$ & $9.3(-01)$ & $3.2(-01)$ & $7.8(-02)$ \\
\hline $\mathrm{H}_{2}^{2} \mathrm{~S} \ldots \ldots \ldots \ldots \ldots$ & $4.0(-01)$ & $2.6(-01)$ & $1.1(-01)$ & $3.1(-02)$ \\
\hline $\operatorname{HCS} \ldots \ldots \ldots \ldots$ & $1.1(+00)$ & $4.3(+00)$ & $1.1(+00)$ & $1.2(+01)$ \\
\hline HNSi ............ & $4.5(-01)$ & $2.4(-01)$ & $8.1(-02)$ & $6.4(-02)$ \\
\hline $\mathrm{PH}_{2} \ldots \ldots \ldots \ldots$ & $2.4(+01)$ & $7.3(-01)$ & $5.3(+01)$ & $1.2(+00)$ \\
\hline $\mathrm{SO}_{2} \ldots \ldots \ldots \ldots$ & $1.0(+00)$ & $7.7(-01)$ & $9.6(-01)$ & $5.0(-02)$ \\
\hline $\mathrm{CH}_{2} \mathrm{CO}$. & $6.9(-01)$ & $6.9(-01)$ & $9.4(-02)$ & $1.9(-01)$ \\
\hline $\mathrm{CH}_{2} \mathrm{NH} \ldots \ldots \ldots \ldots$ & $2.7(-01)$ & $1.6(-01)$ & $2.6(-02)$ & $1.6(-02)$ \\
\hline НСООН ......... & $5.8(-01)$ & $5.2(-01)$ & $2.9(-02)$ & $2.1(-02)$ \\
\hline $\mathrm{SiCH}_{3} \ldots \ldots \ldots \ldots$ & $6.8(-01)$ & $6.8(-01)$ & $9.5(-02)$ & $3.6(-01)$ \\
\hline $\mathrm{CH}_{3} \mathrm{CN} \ldots \ldots \ldots$ & $6.2(-01)$ & $5.2(-01)$ & $5.4(-02)$ & $1.5(-01)$ \\
\hline $\mathrm{CH}_{3} \mathrm{OH} \ldots \ldots \ldots$ & $6.9(-01)$ & $6.1(-01)$ & $2.9(-02)$ & $1.5(-02)$ \\
\hline $\mathrm{C}_{2} \mathrm{H}_{5} \ldots \ldots \ldots \ldots$ & $2.2(+02)$ & $1.1(+02)$ & $5.8(+01)$ & $2.3(+01)$ \\
\hline $\mathrm{C}_{3} \mathrm{H}_{4} \ldots \ldots \ldots \ldots$ & $5.8(-02)$ & $3.2(-01)$ & $6.9(-03)$ & $1.2(-01)$ \\
\hline $\mathrm{CH}_{3} \mathrm{NH}_{2} \ldots \ldots \ldots$ & $4.1(-01)$ & $2.7(-01)$ & $6.1(-02)$ & $3.7(-02)$ \\
\hline $\mathrm{C}_{8} \ldots \ldots \ldots \ldots \ldots$ & $1.2(+00)$ & $6.0(-02)$ & $1.4(+00)$ & $2.0(+00)$ \\
\hline $\mathrm{HCOOCH}_{3} \ldots \ldots$ & $4.4(-01)$ & $4.4(-01)$ & $3.3(-02)$ & $2.2(-02)$ \\
\hline $\mathrm{C}_{8} \mathrm{H} \ldots \ldots \ldots \ldots$ & $5.3(-01)$ & $6.8(-02)$ & $3.9(-01)$ & $1.2(+00)$ \\
\hline $\mathrm{C}_{9} \ldots \ldots \ldots \ldots \ldots$ & $1.6(+00)$ & $6.7(-02)$ & $1.8(+00)$ & $3.2(+00)$ \\
\hline $\mathrm{CH}_{3} \mathrm{OCH}_{3} \ldots \ldots$. & $6.5(-01)$ & $6.1(-01)$ & $7.3(-03)$ & $8.1(-03)$ \\
\hline $\mathrm{CH}_{3} \mathrm{C}_{5} \mathrm{~N} \ldots \ldots \ldots$ & $5.5(-01)$ & $2.8(-01)$ & $8.5(-02)$ & $3.5(-01)$ \\
\hline $\mathrm{CH}_{3} \mathrm{C}_{7} \mathrm{~N} \ldots \ldots \ldots$ & $6.5(-01)$ & $1.6(-01)$ & $8.4(-02)$ & $4.0(-01)$ \\
\hline $\mathrm{C}_{3}^{+} \ldots \ldots \ldots \ldots \ldots$ & $1.3(+00)$ & $1.1(+00)$ & $1.7(+00)$ & $1.1(+01)$ \\
\hline $\mathrm{HSO}^{+} \ldots \ldots \ldots \ldots$ & $8.7(-01)$ & $8.2(-01)$ & $8.3(-01)$ & $5.9(-02)$ \\
\hline $\mathrm{C}_{4}^{+} \ldots \ldots \ldots \ldots \ldots$ & $1.3(+00)$ & $9.1(-01)$ & $2.0(+00)$ & $1.0(+01)$ \\
\hline $\mathrm{CH}_{2} \mathrm{Si}^{+} \ldots \ldots \ldots$ & $1.1(+00)$ & $1.5(+00)$ & $2.3(+00)$ & $1.8(+01)$ \\
\hline $\mathrm{H}_{2} \mathrm{NC}^{+} \ldots \ldots \ldots$ & $3.1(-01)$ & $7.0(-02)$ & $3.4(-01)$ & $8.6(-02)$ \\
\hline $\mathrm{HSO}_{2}^{+} \ldots \ldots \ldots \ldots$ & $1.2(+00)$ & $9.7(-01)$ & $1.1(+00)$ & $4.4(-02)$ \\
\hline $\mathrm{SiC}_{3}^{+} \ldots \ldots \ldots \ldots \ldots$ & $1.3(+00)$ & $9.9(-01)$ & $2.5(+00)$ & $1.6(+01)$ \\
\hline $\mathrm{CH}_{2} \mathrm{CN}^{+} \ldots \ldots \ldots$ & $3.2(+00)$ & $4.7(+00)$ & $3.2(+00)$ & $1.2(+01)$ \\
\hline $\mathrm{SiC}_{4}^{+} \ldots \ldots \ldots \ldots \ldots$ & $5.5(-01)$ & $4.5(-01)$ & $1.0(+00)$ & $1.2(+01)$ \\
\hline $\mathrm{SiC}_{3} \mathrm{H}^{+} \ldots \ldots \ldots \ldots$ & $1.0(+00)$ & $7.3(-01)$ & $1.5(+00)$ & $1.1(+01)$ \\
\hline $\mathrm{C}_{5} \mathrm{H}^{+} \ldots \ldots \ldots \ldots$ & $1.7(+00)$ & $1.1(+00)$ & $2.0(+00)$ & $1.5(+01)$ \\
\hline $\mathrm{NH}_{2} \mathrm{CNH}^{+} \ldots \ldots$ & $2.7(-01)$ & $1.7(-01)$ & $1.2(-01)$ & $3.9(-02)$ \\
\hline $\mathrm{C}_{5} \mathrm{H}_{3} \mathrm{~N}^{+} \ldots \ldots \ldots$ & $2.6(+00)$ & $2.7(+00)$ & $2.0(+00)$ & $1.4(+01)$ \\
\hline $\mathrm{C}_{7} \mathrm{H}_{2}^{+} \ldots \ldots \ldots \ldots$ & $2.4(+00)$ & $9.6(-01)$ & $2.2(+00)$ & $1.5(+01)$ \\
\hline $\mathrm{C}_{9}^{+} \ldots \ldots \ldots+\cdots$ & $1.7(+00)$ & $7.6(-02)$ & $2.0(+00)$ & $4.6(+00)$ \\
\hline $\mathrm{C}_{8} \mathrm{H}_{2}^{+} \ldots \ldots \ldots \ldots$ & $3.3(+00)$ & $4.1(-01)$ & $3.6(+00)$ & $1.1(+01)$ \\
\hline $\mathrm{C}_{9} \mathrm{H}_{2} \mathrm{~N}^{+} \ldots \ldots \ldots$ & $7.6(+00)$ & $5.2(-01)$ & $6.7(+00)$ & $1.4(+01)$ \\
\hline
\end{tabular}

NoTE.-ET is early time and SS is steady state. $a( \pm b)$ means $a \times 10^{ \pm b}$. 
preponderance of larger species in the table. It can also be seen that there is a difference between the two new cases of branching fractions considered.

For the 0.30 case, the effect of the new branching fractions on larger neutral molecules appears in general to be a reduction in abundance that is more heavily concentrated at steady state rather than at early time for strongly unsaturated species. Since only the early-time abundances of large molecules are typically large enough to be compared with observation, the effect of the new branching fractions is even further reduced.

For the 0.05 case, most (but not all) of the neutral molecules showing the most significant changes in abundance in the table contain a number of hydrogen atoms and show reduced abundances, as expected. There are some severe reductions in other molecules such as $\mathrm{SO}_{2}$. No general reduction in the abundances of large unsaturated molecules at steady state is apparent, and there is not as large a dichotomy between steady state and early time.

The results can also be illustrated by plots of the fractional abundances of specific molecules versus time. In Figure 1, we plot the calculated fractional abundance of water (with respect to $\mathrm{H}_{2}$ ) versus time. It can be seen that the storagering-based results ( 0.30 case) are very similar to the old results, while the flowing afterglow-based $(0.05$ case) results show a significant diminution in the water abundance, especially at steady state. In Figure 2, the calculated fractional abundance of methanol, another representative saturated molecule, is shown for the same three models. It can be seen that the methanol abundance as a function of time is reduced with the new branching fractions, but that only the flowing afterglow case results in a serious diminution. In Figure 3, an analogous plot is shown for the complex unsaturated molecule $\mathrm{HC}_{9} \mathrm{~N}$. Here the results for the 0.30 (storage ring) case show little change at early time from the old results but an order-of-magnitude diminution at steady state, when the calculated abundance is already far too low to explain observations. The 0.05 case results show a moderate reduction at early time and no reduction at steady state.

To look at the fate of larger neutral molecules globally, one can ask how the total fractional abundance for neutral

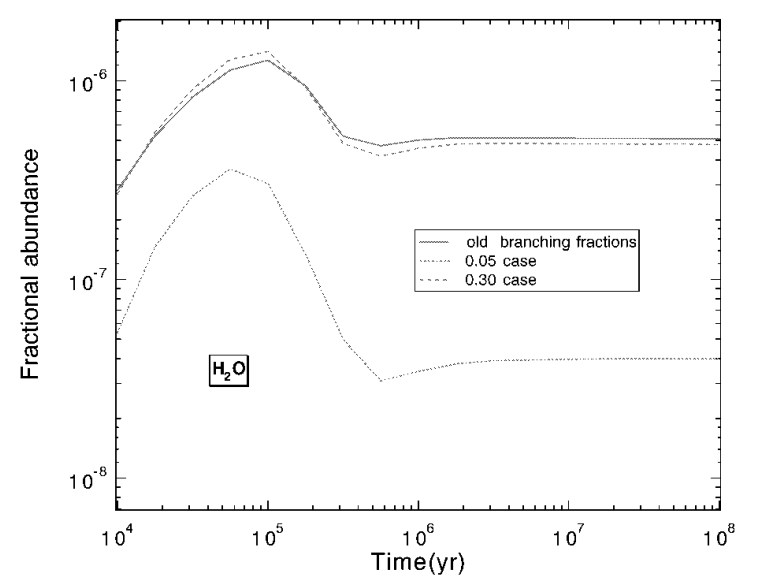

FIG. 1.-Plot of the fractional abundance of water as a function of time for the new standard model with old branching fractions and with new branching fractions, including fractions of 0.30 and 0.05 for suitable atommolecule channels

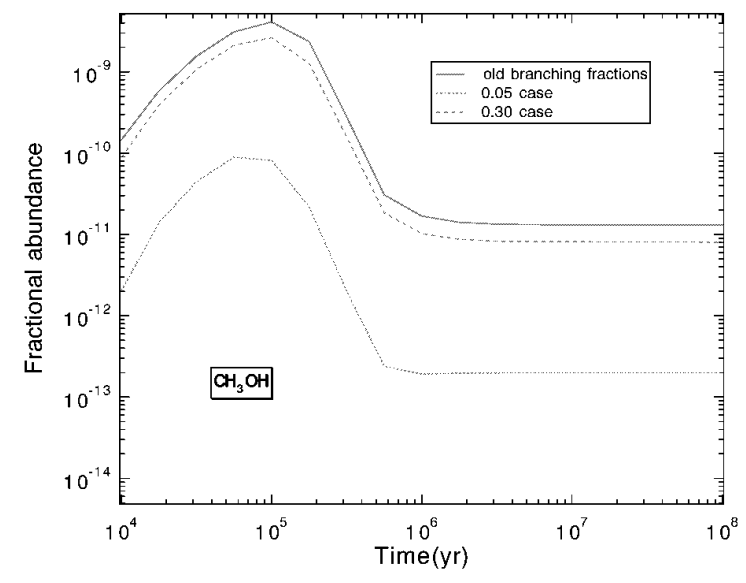

FIG. 2.-Plot of the fractional abundance of methanol as a function of time for the new standard model with old branching fractions and with new branching fractions, including fractions of 0.30 and 0.05 for suitable atom-molecule channels

species larger than or equal to a certain number of atoms $n$ varies with changes in branching fractions. Such total abundances for the three choices of branching fractions are shown in Table 3 as functions of time. When the new branching fractions for both the 0.30 and 0.05 cases are utilized, the overall production of neutral polyatomic molecules at and beyond certain sizes $(5,6,8$, and 9 atoms) generally decreases, but not by a major amount. In addition, the peak abundances shift to slightly smaller times. As opposed to the situation for neutral species, our results show that the new branching fractions lead to slightly higher fractional abundances for electrons and total positive ions, but, again, the global effect is not great. In particular, the fractional electron abundance with the old branching fractions is $4.8 \times 10^{-8}$ at $10^{4} \mathrm{yr}$ and $3.7 \times 10^{-8}$ at steady state, whereas the fractional electron abundance in the 0.30 case is $5.1 \times 10^{-8}$ at $10^{4} \mathrm{yr}$ and $3.9 \times 10^{-8}$ at steady state, and in the 0.05 case it is $5.7 \times 10^{-8}$ at $10^{4} \mathrm{yr}$ and $5.0 \times 10^{-8}$ at steady state. These collective results for both neutrals and ions demonstrate the overall stability of the model results.

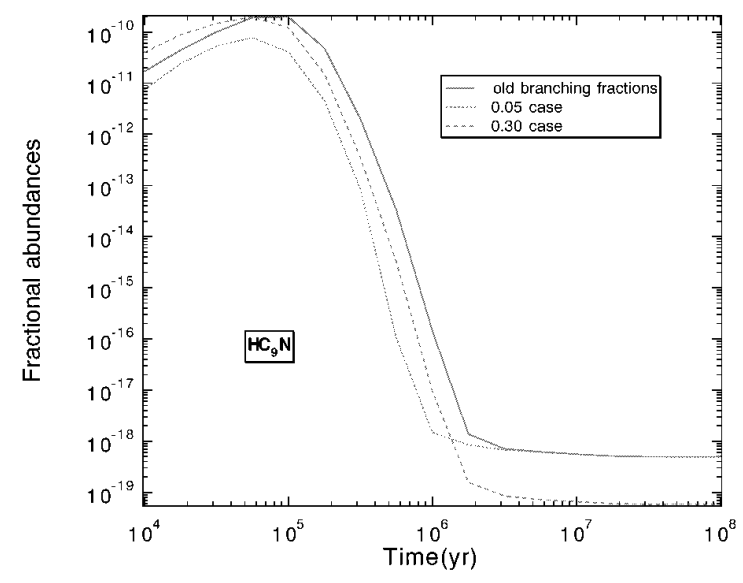

Fig. 3.-Plot of the fractional abundance of $\mathrm{HC}_{9} \mathrm{~N}$ as a function of time for the new standard model with old branching fractions and with new branching fractions, including fractions of 0.30 and 0.05 for suitable atom-molecule channels 
TABLE 3

Total Fractional Abundances with Respect to $\mathrm{H}_{2}$ for Neutral Species with $n$ Atoms OR MORE AS A FunCtion OF TIME

\begin{tabular}{|c|c|c|c|c|c|c|}
\hline$n$ & $1.04(04) \mathrm{yr}$ & $3.2(04) \mathrm{yr}$ & $1.0(05) \mathrm{yr}$ & $3.2(05) \mathrm{yr}$ & $1.0(06) \mathrm{yr}$ & Steady State \\
\hline \multicolumn{7}{|c|}{ Old Branching Fractions } \\
\hline $5 \ldots$ & $4.2(-07)$ & $1.4(-06)$ & $3.3(-06)$ & $3.4(-06)$ & $2.1(-07)$ & $9.8(-08)$ \\
\hline $6 \ldots \ldots$ & $2.5(-08)$ & $7.1(-08)$ & $9.3(-08)$ & $1.3(-08)$ & $8.7(-11)$ & $2.7(-11)$ \\
\hline & $3.8(-09)$ & $1.3(-08)$ & $1.8(-08)$ & $1.6(-09)$ & $3.3(-12)$ & $1.3(-13)$ \\
\hline $9 \ldots \ldots$ & $1.7(-09)$ & $6.0(-09)$ & $1.0(-08)$ & $9.9(-10)$ & $7.6(-13)$ & $7.0(-14)$ \\
\hline \multicolumn{7}{|c|}{ New Branching Fractions -0.30 Case } \\
\hline $5 \ldots \ldots$ & $3.8(-07)$ & $1.3(-06)$ & $3.2(-06)$ & $3.4(-06)$ & $2.1(-07)$ & $1.1(-07)$ \\
\hline $6 \ldots \ldots$ & $2.6(-08)$ & $6.8(-08)$ & $5.9(-08)$ & $7.2(-09)$ & $5.2(-11)$ & $1.9(-11)$ \\
\hline $8 \ldots \ldots$ & $6.1(-09)$ & $1.3(-08)$ & $9.4(-09)$ & $4.8(-10)$ & $7.0(-13)$ & $5.8(-14)$ \\
\hline $9 \ldots \ldots$ & $2.0(-09)$ & $4.6(-09)$ & $5.1(-09)$ & $3.1(-10)$ & $2.5(-13)$ & $4.0(-14)$ \\
\hline \multicolumn{7}{|c|}{ New Branching Fractions -0.05 Case } \\
\hline $5 \ldots \ldots$ & $2.1(-07)$ & $9.2(-07)$ & $2.5(-06)$ & $1.9(-06)$ & $1.4(-07)$ & $1.3(-07)$ \\
\hline $6 \ldots \ldots$ & $1.7(-08)$ & $5.4(-08)$ & $3.5(-08)$ & $2.7(-09)$ & $1.1(-11)$ & $9.4(-12)$ \\
\hline $8 \ldots \ldots$ & $4.0(-09)$ & $1.0(-08)$ & $5.1(-09)$ & $1.4(-10)$ & $2.0(-13)$ & $1.2(-13)$ \\
\hline $9 \ldots \ldots$ & $1.2(-09)$ & $3.1(-09)$ & $1.9(-09)$ & $5.1(-11)$ & $6.2(-14)$ & $4.3(-14)$ \\
\hline
\end{tabular}

NoTE. $-a( \pm b)$ means $a \times 10^{ \pm b}$

In Table 4, we compare observed fractional abundances for molecules in TMC-1 (Ohishi, Irvine, \& Kaifu 1992) with early-time results based on the old branching fractions and the two new cases considered. It can be seen immediately that there is little difference between the results with the old branching fractions and the results with the new, storagering-based fractions, both of which lead to excellent agreement with observation. There is, however, a significant difference between the old results and the results with the flowing afterglow-based branching fractions for a select group of mainly saturated molecules, a difference that on balance worsens the agreement with observation.

\section{DISCUSSION}

The storage ring results on the products of a small number of dissociative recombination reactions appear to indicate that, as included previously in chemical models of interstellar clouds, product channels in which only a hydrogen atom is removed from the molecular skeleton are competitive with other channels. On the other hand, the results indicate that three-body product channels are also prominent, showing that fragmentation can be more severe than assumed in the standard interstellar chemical models. Based on the limited data available so far, we have reestimated the product branching fractions for all of the dissociative recombinations in our "new standard model" involving molecular ions with four or more atoms. The revised network has been labeled the 0.30 case, in reference to the generally adopted approximate branching fraction for the $\mathrm{H}_{2} \mathrm{O}+\mathrm{H}$ channel in the dissociative recombination of $\mathrm{H}_{3} \mathrm{O}^{+}+e$. In the new estimations, more severe fragmentation is assumed. The model results show that for large unsaturated neutral species the new branching fractions frequently have only a minor effect on early-time abundances and a more severe effect on steady state abundances, where sizeable diminutions can occur. However, since our predicted concentrations of complex molecules are only large enough to explain observed values at early time, the effect of the new branching fractions based on the storage ring results is not severe at all, as can be seen in the comparison with observation in TMC-1 in Table 4. Part of the reason for the relatively small effect lies in the strong chemical bonds present in large unsaturated molecular ions. With these strong bonds, it is often not possible to break more than one of them during dissociative recombination. Another reason lies in the existence of competitive neutralneutral reaction pathways.

Based on the assumption that some unforeseen error is occurring in the storage ring experiments such that the results of the flowing afterglow experiment on $\mathrm{H}_{3} \mathrm{O}^{+}+e$ are correct and capable of generalization, we have run a model based on such a generalization. The model (the 0.05 case) shows a more focused effect, which is to reduce significantly the calculated abundances of a group of relatively hydrogen-rich molecules, although some saturated species such as $\mathrm{NH}_{3}$ and $\mathrm{CH}_{4}$ do not show strongly reduced abundances. These two exceptions arise differently: for $\mathrm{NH}_{3}$ the $\mathrm{H}$ atom-ammonia channel of $\mathrm{NH}_{4}^{+}+e^{-}$is assumed to be marginally stable, whereas for $\mathrm{CH}_{4}$ the species is produced via a deprotonation reaction between the precursor ion $\mathrm{CH}_{5}^{+}$and $\mathrm{CO}$. Not all of the species in Table 2 due to major changes in the 0.05 (flowing afterglow) case are hydrogenrich; $\mathrm{SO}_{2}$ shows strongly lowered abundances at steady state if not at early time, a change related in a nonsimple manner to our downweighting of the $\mathrm{H}-\mathrm{SO}_{2}$ channel in the dissociative recombination of $\mathrm{HSO}_{2}^{+}$.

In the comparison in Table 4, it can be seen that aggravated discrepancies between theory ( 0.05 case) and observation in TMC-1 ( $\geq$ order of magnitude) occur for the following molecules: $\mathrm{H}_{2} \mathrm{~S}, \mathrm{H}_{2} \mathrm{CS}, \mathrm{CH}_{3} \mathrm{OH}, \mathrm{CH}_{3} \mathrm{CHO}$ (acetaldehyde), $\mathrm{C}_{3} \mathrm{H}_{4}$ (methyl acetylene), and $\mathrm{CH}_{3} \mathrm{C}_{3} \mathrm{~N}$ (methyl cyanoacetylene), all of which are H-rich. The predicted peak abundances of these species in the 0.05 case are all considerably too low, mainly because of the reduction in the importance of $\mathrm{H}$ atom-molecule dissociative recombination product channels. Similar large reductions occur for other species $\left(\mathrm{HCOOH}, \mathrm{CH}_{3} \mathrm{CN}, \mathrm{CH}_{3} \mathrm{C}_{4} \mathrm{H}\right.$ or methyl diacetylene) without worsening the agreement with observation, although the newly calculated peak abundances tend to be low rather than high. Methanol is reduced in abundance both via the smaller branching fraction for the $\mathrm{CH}_{3} \mathrm{OH}+\mathrm{H}$ channel of $\mathrm{CH}_{3} \mathrm{OH}_{2}^{+}+e^{-}$and via the 
TABLE 4

Calculated Fractional Abundances with Respect to $\mathrm{H}_{2}$ at Early TIME $\left(10^{5}\right.$ YeARS $)$ COMPARED WITH VALUES FOR TMC- 1

\begin{tabular}{|c|c|c|c|c|}
\hline Species & TMC-1 & 0.30 Case & 0.05 Case & Old \\
\hline $\mathrm{C}_{2} \ldots \ldots$ & $5(-08)$ & $2(-08)$ & $3(-08)$ & $3(-08)$ \\
\hline $\mathrm{CH} \ldots \ldots$ & $2(-08)$ & $6(-09)$ & $8(-09)$ & $7(-09)$ \\
\hline $\mathrm{CN} \ldots$ & $3(-08)$ & $1(-07)$ & $1(-07)$ & $1(-07)$ \\
\hline $\mathrm{CO}$. & $8(-05)$ & $9(-05)$ & $9(-05)$ & $9(-05)$ \\
\hline $\mathrm{CS} \ldots \ldots$ & $1(-08)$ & $6(-09)$ & $7(-09)$ & $7(-09)$ \\
\hline NO ............ & $3(-08)$ & $5(-09)$ & $4(-09)$ & $6(-09)$ \\
\hline OH $\ldots \ldots \ldots \ldots \ldots$ & $3(-07)$ & $1(-08)$ & $1(-08)$ & $1(-08)$ \\
\hline SO ............. & $5(-09)$ & $8(-10)$ & $6(-10)$ & $8(-10)$ \\
\hline $\mathrm{C}_{2} \mathrm{H} \ldots \ldots \ldots \ldots$ & $5(-08)$ & $9(-08)$ & $9(-08)$ & $7(-08)$ \\
\hline $\mathrm{C}_{2} \mathrm{~S} \ldots \ldots \ldots \ldots \ldots$ & $8(-09)$ & $2(-09)$ & $2(-09)$ & $3(-09)$ \\
\hline $\mathrm{C}_{2} \mathrm{O} \ldots \ldots \ldots \ldots$ & $6(-10)$ & $3(-10)$ & $2(-10)$ & $1(-10)$ \\
\hline $\mathrm{H}_{2} \mathrm{~S} \ldots \ldots \ldots \ldots$ & $5(-10)$ & $8(-12)$ & $2(-12)$ & $2(-11)$ \\
\hline $\mathrm{HCN} \ldots .$. & $2(-08)$ & $2(-07)$ & $1(-07)$ & $2(-07)$ \\
\hline HNC $\ldots \ldots \ldots \ldots$ & $2(-08)$ & $9(-08)$ & $2(-08)$ & $8(-08)$ \\
\hline OCS ............. & $2(-09)$ & $3(-09)$ & $2(-09)$ & $3(-09)$ \\
\hline $\mathrm{SO}_{2} \ldots \ldots \ldots \ldots$ & $1(-09)$ & $1(-10)$ & $8(-11)$ & $1(-10)$ \\
\hline $\mathrm{C}_{3} \mathrm{H} \ldots \ldots \ldots \ldots$ & $5(-10)$ & $5(-08)$ & $4(-08)$ & $4(-08)$ \\
\hline $\mathrm{C}_{3} \mathrm{~N} \ldots \ldots \ldots \ldots$ & $1(-09)$ & $2(-08)$ & $2(-08)$ & $2(-08)$ \\
\hline $\mathrm{C}_{3} \mathrm{O} \ldots \ldots \ldots \ldots$ & $1(-10)$ & $2(-11)$ & $2(-11)$ & $3(-11)$ \\
\hline $\mathrm{C}_{3} \mathrm{~S} \ldots \ldots \ldots \ldots \ldots$ & $1(-09)$ & $4(-10)$ & $3(-10)$ & $8(-10)$ \\
\hline $\mathrm{H}, \mathrm{CO} \ldots \ldots \ldots$ & $2(-08)$ & $1(-07)$ & $8(-08)$ & $1(-07)$ \\
\hline $\mathrm{H}_{2}^{2} \mathrm{CS} \ldots \ldots \ldots$ & $3(-09)$ & $2(-10)$ & $4(-11)$ & $4(-10)$ \\
\hline $\mathrm{NH}_{3} \ldots \ldots \ldots \ldots$ & $2(-08)$ & $2(-09)$ & $9(-10)$ & $4(-09)$ \\
\hline $\mathrm{CH}_{2} \mathrm{CN} \ldots \ldots \ldots$ & $5(-09)$ & $4(-08)$ & $2(-08)$ & $5(-08)$ \\
\hline $\mathrm{CH}_{2} \mathrm{CO} \ldots \ldots \ldots$ & $1(-09)$ & $2(-08)$ & $3(-09)$ & $4(-08)$ \\
\hline $\mathrm{C}_{3} \mathrm{H}_{2} \ldots \ldots \ldots \ldots$ & $1(-08)$ & $2(-08)$ & $2(-08)$ & $2(-08)$ \\
\hline $\mathrm{C}_{4} \mathrm{H} \ldots \ldots \ldots \ldots$ & $2(-08)$ & $6(-08)$ & $5(-08)$ & $1(-07)$ \\
\hline $\mathrm{HCOOH} \mathrm{......}$ & $2(-10)$ & $7(-10)$ & $4(-11)$ & $1(-09)$ \\
\hline $\mathrm{HC}_{3} \mathrm{~N} \ldots \ldots \ldots$ & $6(-09)$ & $7(-08)$ & $5(-08)$ & $1(-07)$ \\
\hline $\mathrm{CH}_{3} \mathrm{CN} \ldots \ldots \ldots$ & $1(-09)$ & $5(-09)$ & $3(-10)$ & $1(-08)$ \\
\hline $\mathrm{C}_{4} \mathrm{H}_{2} \ldots \ldots \ldots \ldots$ & $8(-10)$ & $2(-08)$ & $2(-08)$ & $2(-08)$ \\
\hline $\mathrm{C}_{5} \mathrm{H} \ldots \ldots \ldots \ldots$ & $3(-10)$ & $2(-09)$ & $2(-09)$ & $4(-09)$ \\
\hline $\mathrm{CH}_{3} \mathrm{OH} \ldots \ldots \ldots$ & $2(-09)$ & $3(-09)$ & $8(-11)$ & $4(-09)$ \\
\hline $\mathrm{CH}_{3} \mathrm{CHO} . . .$. & $6(-10)$ & $2(-11)$ & $2(-12)$ & $1(-11)$ \\
\hline $\mathrm{C}_{2} \mathrm{H}_{3} \mathrm{CN} \ldots \ldots$. & $2(-10)$ & $7(-10)$ & $2(-10)$ & $6(-10)$ \\
\hline $\mathrm{C}_{3} \mathrm{H}_{4} \ldots \ldots \ldots \ldots$ & $6(-09)$ & $3(-10)$ & $4(-11)$ & $4(-09)$ \\
\hline $\mathrm{C}_{6} \mathrm{H} \ldots \ldots \ldots \ldots$ & $1(-10)$ & $2(-09)$ & $1(-09)$ & $3(-09)$ \\
\hline $\mathrm{HC}_{5} \mathrm{~N} \ldots \ldots \ldots$ & $3(-09)$ & $7(-09)$ & $3(-09)$ & $1(-08)$ \\
\hline $\mathrm{CH}_{3} \mathrm{C}_{3} \mathrm{~N} \ldots \ldots$. & $5(-10)$ & $3(-10)$ & $6(-11)$ & $1(-09)$ \\
\hline $\mathrm{CH}_{3} \mathrm{C}_{4} \mathrm{H} \ldots \ldots$. & $2(-10)$ & $2(-09)$ & $6(-10)$ & $5(-09)$ \\
\hline $\mathrm{HC}_{7} \mathrm{~N} \ldots \ldots \ldots$ & $1(-09)$ & $9(-10)$ & $4(-10)$ & $2(-09)$ \\
\hline $\mathrm{HC}_{9} \mathrm{~N} \ldots \ldots \ldots$ & $3(-10)$ & $1(-10)$ & $4(-11)$ & $2(-10)$ \\
\hline $\mathrm{HCO}^{+} \ldots \ldots \ldots$ & $8(-09)$ & $4(-09)$ & $4(-09)$ & $4(-09)$ \\
\hline $\mathrm{HCS}^{+} \ldots \ldots \ldots \ldots$ & $6(-10)$ & $9(-12)$ & $1(-11)$ & $1(-11)$ \\
\hline $\mathrm{N}_{2} \mathrm{H}^{+} \ldots \ldots \ldots$ & $5(-10)$ & $3(-13)$ & $3(-13)$ & $3(-13)$ \\
\hline $\mathrm{H}_{2} \mathrm{CN}^{+} \ldots \ldots \ldots$ & $2(-09)$ & $2(-09)$ & $1(-09)$ & $8(-10)$ \\
\hline
\end{tabular}

NOTE. $-a( \pm b)$ means $a \times 10^{ \pm b}$.

reduced abundance of the precursor water, which associates with the methyl ion $\left(\mathrm{CH}_{3}^{+}\right)$to produce $\mathrm{CH}_{3} \mathrm{OH}_{2}^{+}$. Despite the problems with $\mathrm{H}$-rich species, it must be noted that most of the many observed molecules in TMC-1 can still be accounted for by the new standard model at early time even with the flowing afterglow-based branching fractions, although the time range of agreement is often reduced. Saturated molecules are the most likely to be produced on grain surfaces, but desorption into the gas is problematical. Agreement between the observed abundances in TMC-1 and the results of other networks with large numbers of rapid neutral-neutral reactions (the new neutral-neutral model and model 4) is generally worse but is improved by increasing the value of the carbon-to-oxygen elemental abundance ratio (Terzieva \& Herbst 1997). Recent work on the sensitivity of model results to this ratio has also been reported by Bergin et al. (1997). As for the sensitivity of the new neutral-neutral model to changes in dissociative recombination branching fractions, we have run a calculation with the flowing afterglow-based fractions, and we find a similar but slightly stronger sensitivity than in the new standard model.

The effects on calculated abundances resulting from changes in product branching fractions for dissociative recombination reactions are based on model networks in which such processes are the sole mechanism for converting positive ions into neutral species. Competitive positive ionnegative ion recombination processes involving the negative ions of large molecules may also occur if such large molecules are both abundant and have electron affinities sufficiently sizeable that their negative ions are likely to form via sticking reactions with electrons (Herbst 1981; Lepp \& Dalgarno 1988), as might occur for certain classes of polycyclic aromatic hydrocarbons (Allamandola, Tielens, $\&$ Barker 1989). Since the exothermicities of these recombination reactions are smaller than the analogous reactions with electrons and since reaction energy can be deposited in the large molecules, dissociation of the product neutrals cannot proceed to as large an extent (Bates \& Herbst 1988), although the branching fractions are poorly understood. Positive ion-negative ion recombination reactions are not included in our present models, but are a likely target of future investigation.

E. H. acknowledges the support of the National Science Foundation for his research program in astrochemistry. He also wishes to thank the Ohio Supercomputer Center for computer time on their Cray Y-MP/8.

\section{REFERENCES}

Adams, N. G. 1992, in Advances in Gas Phase Chemistry, Vol. 1, ed. N. G. Adams \& L. M. Babcock (Greenwich: JAI), 271

Adams, N. G., et al. 1991, J. Chem. Phys., 94, 4852

Adams, N. G., \& Smith, D. 1988, in Rate Coefficients in Astrochemistry, ed. T. J. Millar \& D. A. Williams (Dordrecht: Kluwer), 173

Allamandola, L. J., Tielens, A. G. G. M., \& Barker, J. R. 1989, ApJS, 71, 733

Bates, D. R. 1989, ApJ, 344, 531

Bates, D. R., \& Herbst, E. 1988, in Rate Coefficients in Astrochemistry, ed. T. J. Millar \& D. A. Williams (Dordrecht: Kluwer), 41

Bergin, E. A., Goldsmith, P. F., Snell, R. L., \& Langer, W. D. 1997, ApJ, 482,285

Bettens, R. P. A., \& Herbst, E. 1995, Int. J. Mass Spectrom. Ion Processes, $149 / 150,321$

Bettens, R. P. A., Lee, H. H., \& Herbst, E. 1995, ApJ, 443, 664

Dalgarno, A. 1994, Adv. At. Mol. Opt. Phys., 32, 57
Datz, S., et al. 1995a, Phys. Rev. Lett., 74, 896

Datz, S., et al. 1995b, Phys. Rev. A, 52, 2901

Galloway, E. T., \& Herbst, E. 1991, ApJ, 376, 531

Herbst, E. 1981, Nature, 289, 656

Herbst, E., \& Klemperer, W. 1973, ApJ, 185, 505

Herbst, E., \& Leung, C. M. 1989, ApJS, 69, 271

Herd, C. R., Adams, N. G., \& Smith, D. 1990, ApJ, 349, 388

Larsson, M. et al. 1996, A\&A, 309, L1

Le Bourlot, J., Pineau des Forêts, G., \& Roueff, E. 1995, A\&A, 297, 251

Lee, H.-H., Bettens, R. P. A., \& Herbst, E. 1996a, A\&AS, 119, 111

Lee, H.-H., Herbst, E., Pineau des Forêts, G., Roueff, E., \& Le Bourlot, J. 1996b, A\&A, 311, 690

Lepp, S., \& Dalgarno, A. 1988, ApJ, 324, 553

Millar, T. J., DeFrees, D. J., McLean, A. D., \& Herbst, E. 1988, A\&A, 194 250

Millar, T. J., Farquhar, P. R. A., \& Willacy, K. 1997, A\&AS, 121, 139 
Mitchell, J. B. A. 1990, Phys. Rep., 186, 215

Ohishi, M., Irvine, W. M., \& Kaifu, N. 1992, in Astrochemistry of Cosmic Phenomena, ed. P. D. Singh (Dordrecht: Kluwer), 171

Sims, I., \& Smith, I. W. M. 1995, Ann. Rev. Phys. Chem., 46, 109

Smith, D., \& Spanel, P. 1993, Int. J. Mass Spectrom. Ion Processes, 129, 163
Sundström, G., et al. 1994, Science, 263, 785

Terzieva, R., \& Herbst, E. 1997, in preparation

Vejby-Christensen, L., Andersen, L. H., Heber, O., Kella, D., Pedersen,

H. B., Schmidt, H. T., \& Zaifman, D. 1997, ApJ, 483, 531

Williams, T. L., Adams, N. G., Babcock, L. M., Herd, C. R., \& Geoghegan, M. 1996, MNRAS, 282, 413 